\title{
Immunization strategies and enhanced immunity of typhoid vaccine using potato starch polymer as an adjuvant
}

\author{
L. Nirmala, Vijayashree Nayak, Sanjay Kumar Dhaker and Deecaraman \\ Department of Industrial Biotechnology, Dr. MGR Educational Research Institute, Chennai 600 095, India
}

snwiar@yahoo.co.in

\begin{abstract}
Controlled release of typhoid antigen encapsulated potato starch microparticles minimize the disadvantages in terms of cost, multiple doses and side effects. The development of this work may enable to replace the alum to elicit sustained immune response because alum induces local granuloma and hypersensitivity reaction to some individuals. We have employed emulsion crosslinking technique by using $0.5 \% \mathrm{ml}$ glutaraldehyde as a crosslinking agent. The particle size was analyzed as $43.34 \mu \mathrm{m}$; the loading capacity was about $44.76 \%$ and the loading efficiency as about $75.17 \%$, while the morphology was unchanged in the stability studies. In vitro studies were analyzed by SEM and compatibility studies were performed by IR $\alpha$ F.T spectroscopic analysis. The percentage of antigenically active typhoid antigens was found to be $91.5 \%$ by ELISA after entrapment with $8 \%$ of starch and $0.5 \%$ of stabilizing agent. Immunoprecipitation assay exhibited that the amount of antigen in the sample was found to be $51 \mu \mathrm{g}$ and at the dilution of 1:50 showed agglutination factor (with the titer value of 50 ).
\end{abstract}

Keywords: Typhoid, potato starch, biodegradability, immunomodulatory, single therapy, antibody response.

\section{Introduction}

The worldwide use of vaccines over the last few decades has brought down the incidence of many infectious diseases in the developed countries. Nevertheless, there are still significant challenges for vaccine development including the need to make improvement in existing vaccine by making them safer, more immunogenic and extending the vaccine coverage to certain population, particularly in the developing world (Davis, 1998). One of the most important issues in vaccinology is the need for new adjuvant in vaccine delivery system (Hans \& Hagan, 1997). Most of the vaccines currently in development are based on purified subunits, recombinant molecule, synthetic peptides or nucleic acids which are often poorly immunogenic, expensive and produce adverse effect (Kalara et al., 2003). It is clear that new generation of vaccines will require better adjuvant delivery systems to induce optimal immune response.

Typhoid (cloudy) fever is the systemic infection, caused mainly by S. typhi characterized by a continuous fever for 3-4 weeks, with involvement of lymphoid tissue and considerable constitutional symptoms (Morein et al., 1996). Antibiotics resistance, particularly emergence of multidrug resistant (MDR) strains among salmonellae, is also a rising concern and has recently been linked to antibiotic use in livestock (Singh et al., 1998). Many S. typhi strains contain plasmids encoding resistance chloramphenicol, ampicillin and co-trimoxazole, the antibiotics that have been long used to treat enteric fever. In addition, resistance to ciprofloxacin also called nalidixic acid resistant S.typhi strain either chromosomally or plasmid encoded, has been observed in Asia (Yadav \& Montae, 2008). The chemotherapy of typhoid is complicated by the need of multidrug regiments that need to be administered over long periods, poor patient compliance, toxicity, tachycardia, bradycardia, myalgia, hyperplasia, necrosis, enterocolitis, peyer's patches (Lewis \& Chasin,1998). Extensive progressive efforts have been made to develop various microspheres as potential carriers to increase potential outcomes. The system under discussion employ either biodegradable polymer or system requiring removal after use and can release the drug either by membrane or matrix- controlled diffusion. Recent trends in potential carrier delivery have seen microencapsulation of pharmaceutical substances in biodegradable polymers as an emerging technology. Currently, biodegradable polymer representing class of ubiquitous material and are being shown in the macromolecules by the fabrication vaccine system (Seong et al, 1998). Biodegradable polymer in the form of microsphere has shown the ideal perquisite microsphere carrier to the vaccine delivery system for long lasting immune responses in single dose. (Morein \& Villacrks, 1996).

The adjuvant effect achieved as a consequence of the encapsulation of antigens in microparticles which has been known for many years. The enhanced immunogenicity of particulate antigens is unsurprising, since pathogens are particulates of similar dimensions and the immune system has evolved to deal with these. Particulates delivery system presents multiple copies of antigens to the immune system and promote trapping and retention of antigen in local lymph node moreover particles are taken up by macrophages and dendrite cells leading to enhanced antigen penetration and the release of cytokines to promote the induction of an immune response (Fiegel et a/ 2004). Sustaining response for a longer duration including local mucosal immune response, generating antibody with increased avidity and
Research article

CIndian Society for Education and Environment (iSee)
"Improved typhoid vaccine" http://www.indjst.org
Nirmala et al. Indian J.Sci.Technol. 
neutralization capacity eliciting cytotoxic $\mathrm{T}$ lymphocyte (CTLs) to enhances immune response.

This paper describes the use of microparticles as a potential adjuvant for Typhoid antigen. The immune responses of the antigen loaded microparticles were compared with the conventional typhoid vaccine. Starch can be modified through physical, chemical or enzymatic processes (Singh \& O'Hagan, 1998). Cross linked starches have long been used as food additives because of their safety and low cost. Very low levels are used and these are approved by the FDA (CFR 172.892). Different covalent cross-linking agents have been used (Sacchez et al., 1999).

\section{Materials and methods}

Soluble potato starch was obtained from Hi-media, Free sample of Typhoid antigen was obtained from Serum Institute of India (Guindy) Chennai, Other materials include: Organic solvent of AR grade; Tween80 from Hi-media and Glutaraldehyde (spectrochemicals). Typhoid vaccine encapsulated starch microparticles were prepared by microencapsulation techniques (Emulsion crosslinking) (Yadav \& Montae, 2008). Based upon the result obtained with different parameters such as polymer concentration and concentration of crosslinking agent various batches were prepared to standardize an ideal batch. Starch solution $(1 \%$ to $10 \% / \mathrm{ml})$ was prepared in a $250 \mathrm{ml}$ beaker by continuous stirring for one hour at $5000 \mathrm{rpm}$. An emulsion was made by mixing the vegetable oil and toluene with two drops of Tween-80. To the gel $1 \mathrm{ml}$ of typhoid antigen and $1 \mathrm{ml}$ of $0.5 \%$ Glutaraldehyde was added and stirring was continued for one hour. $2 \mathrm{ml}$ of gel containing typhoid antigen was added into the emulsion with continuous stirring. At the end, the precipitates were centrifuged and washed with various organic solvents to obtain white powder (microspheres). Many batches were formulated, pooled and stored in a refrigerator at $4^{\circ} \mathrm{C}$.

\section{Preparation and characterization of microparticles}

The morphology and size distribution of dried microspheres was evaluated by Scanning Electron Microscopy and the size of the microparticles was determined by optical microscope using calibrated scale. The magnitude of loading Typhoid antigen in microparticles was performed by mixing with phosphate buffer saline $(\mathrm{pH} \mathrm{7.4)}$ under shaking at room temperature kept for $3 \mathrm{hrs}$. The suspension was centrifuged at 4000 rpm for 15 min to remove free antigen and analyzed by Lowry' method (Dubey et al. 2006).

Total amount of antigen- Free antigen

Loading capacity $\%=$

$$
\text { Wt of micro particles }
$$

Total amount of antigen- Free antigen

Loading efficiency $\%=$

$$
\text { Total amount of antigen }
$$

The stability of the formulated typhoid antigen encapsulated starch microparticles and unloaded starch microparticles were determined over a week period. Both antigens loaded and unloaded micro particles were kept at $4^{0} \mathrm{C}$. At predetermined time intervals the samples were taken at $0,1,2,3,4,5,6$, and 7 days. The morphology was determined by light microscope and the size was determined by using stage-eyepiece micrometer.

The swelling ratio of the starch microparticles was determined as the percentage of particle size change after incubation in the phosphate buffer $(\mathrm{pH} 7.4)$. Wt of microparticles with similar diameter were chosen. Diameter of the beads was measured before and after incubating in phosphate buffer $(\mathrm{pH} 7.4)$ for 12 hours under optical microscope. The swelling percent was calculated as follow:

Diameter in swollen state - Diameter in dry state $\%$ Swelling ratio $=\frac{\text { Diameter in dry state }}{\text { Compatibility study was performed by Infrared }}$
. Spectroscopy and the integrity of antigen was studied by SDS PAGE and ELISA.

In vitro release profile

$200 \mathrm{mg}$ of Typhoid antigen encapsulate micro particles were taken in a $250 \mathrm{ml}$ conical flask and $50 \mathrm{ml}$ of PBS (pH7.4) was added. The flask was kept in the shaker cum incubator. The shaker was adjusted to 80 horizontal strokes per min at $37{ }^{\circ} \mathrm{C}$. From this $1 \mathrm{ml}$ of solution was taken in test tube and fresh PBS was added immediately in to the flask. This process was repeated at various predetermined time intervals of $2 \mathrm{hrs}, 4 \mathrm{hrs}, 6 \mathrm{hrs}, 8 \mathrm{hrs}$, $10 \mathrm{hrs}, 12 \mathrm{hrs}, 14 \mathrm{hrs}, 16 \mathrm{hrs}, 18 \mathrm{hrs}$ and $20 \mathrm{hrs}$. The collected samples were centrifuged and supernatant solution analyzed by Bronsted Lowrys method.

Immunogenicity studies

Immunoprecipitation test

The precipitation reaction was carried out for a quantitative estimation of antibody in a serum, by mixing different dilutions of the antigen to the same volume of the antiserum. The mixture was first incubated at $37^{\circ} \mathrm{C}$ for an hour, and then at $4^{0} \mathrm{C}$ for a longer period. The materials in each tube series were then centrifuged and supernatant was tested for excess antibody or antigen. Then the precipitate was dissolved in $0.1 \mathrm{ml}$ of $\mathrm{NaOH}$ and optical density was measured of solution at $280 \mathrm{~nm}$. The amount of antigen was calculated.

Hemagglutination test (Widal test)

The serological method used in the diagnosis of enteric fever (typhoid \& para typhoid fever) is caused by S. typhi. $2 \mathrm{ml}$ of sample was taken in to $10 \mathrm{ml}$ of PBS and kept as stock solution for further dilutions. $1 \mathrm{ml}$ of sample with $10 \mathrm{mIPBS}$ and $0.2 \mathrm{ml}$ of saline was added and made into serial dilution as (1:12:5) The master dilution was made with $0.2 \mathrm{ml}$ of saline, finally $0.2 \mathrm{ml}$ of antigen (blood) was added in to it.

Bleeding of immunized Wister rats was done by Retro orbital plexus by using a capillary tube. The samples were pooled and serum was separated. The serum sampled was analyzed by ELISA. The potency of typhoid 
vaccine encapsulated starch microparticles was tested by measuring the specific antibody by immunoprecipitation assay. The Ig titer was found by immunoprecipatation assay with Nephelometric endpoint.

\section{Result and discussion}

Scanning electron microscopy was performed in order to assess the morphology and size of the micropaticles formulation of typhoid antigen encapsulated starch microparticles. The antigen unloaded microparticles was found to be irregular in size and shape (Fig.1) while the antigen loaded starch microparticles are homogenous and shown to be more or less with spherical geometry (Fig.2). By differential analysis it was found that the loading of antigen into the microparticles and the size of the microparticles were greatly influenced by stabilizing agent and the polymer concentration (Table 1 \& $2)$. The loaded particles become smooth surfaced with reduced size compared to unloaded particles (Table 3). The average size of microparticles was found to be 43.34 $\mu \mathrm{m}$ (Table 4).

The loading capacity was about $44.76 \%$ and the loading efficiency as about $75.17 \%$ (Table 4). Regarding stabilities studies, the morphology of typhoid antigen encapsulated starch microparticles were not changed at $4^{0} \mathrm{C}$ at room temperature but not in $50^{\circ} \mathrm{C}$. The water uptake of the microparticles after $24 \mathrm{hrs}$ of incubation leads to bursting

Table 1. The effect of the polymer concentration by using $0.5 \%$ of glutaraldehyde as a stabilizing agent

\begin{tabular}{|c|c|c|c|c|}
\hline Polymer & $\begin{array}{l}\text { Polymer } \\
\text { conc. }\end{array}$ & $\begin{array}{l}\text { Stabilizing } \\
\text { agent }\end{array}$ & $\begin{array}{c}\text { Conc. of } \\
\text { stabilizing } \\
\text { agent (\%) }\end{array}$ & Size \& shape \\
\hline \multirow{9}{*}{ Starch } & $1 \%$ & \multirow{9}{*}{ 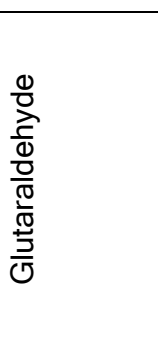 } & \multirow{9}{*}{$0.5 \%$} & Micro particles are not formed \\
\hline & $2 \%$ & & & Micro particles are not formed \\
\hline & $3 \%$ & & & Micro particles are not formed \\
\hline & $4 \%$ & & & Micro particles are not formed \\
\hline & $5 \%$ & & & Micro particles are not formed \\
\hline & $6 \%$ & & & Micro particles are not formed \\
\hline & $7 \%$ & & & Micro particles are not formed \\
\hline & $8 \%$ & & & Micro particles are formed \\
\hline & $9 \%$ & & & Clumping occurs \\
\hline
\end{tabular}

of the microparticles. Therefore, it is presumed that water penetrates into the microparticles, and dissolves the stabilizing agent.
Fig. 1. Antigen unloaded microparticles
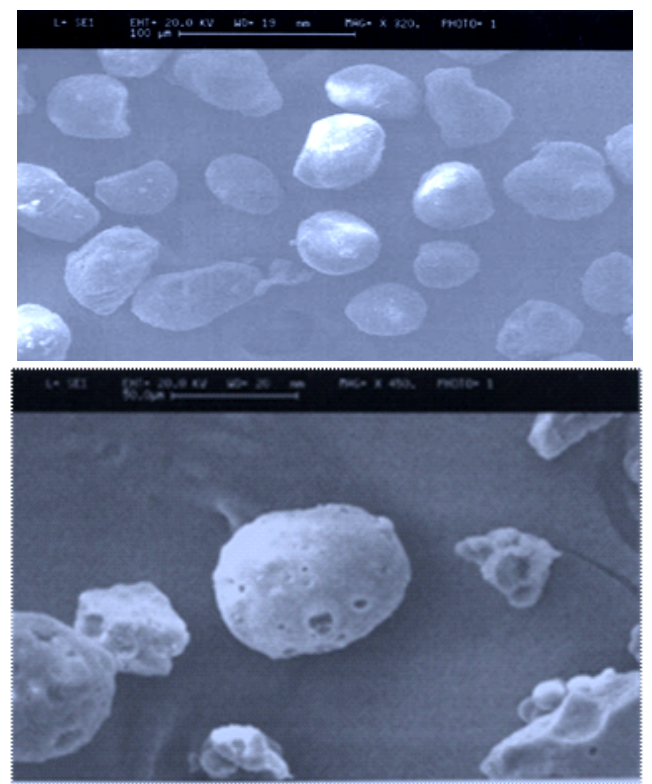

Fig.2. Antigen loaded micropartlcles

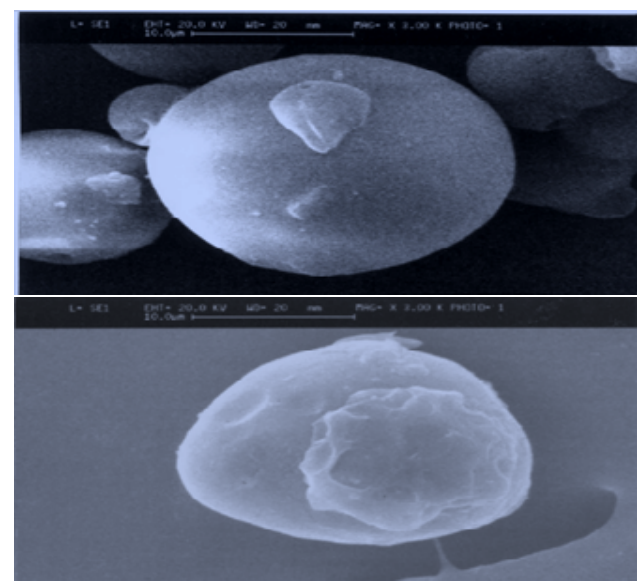

\section{SDS PAGE gel electrophoresis}

SDS gel electrophoresis reveals that as the pore size of the microparticles increases the antigen release also enhanced which lead to the bursting effect. The integrity of the entrapped antigen was evaluated by SDSPAGE and ELISA. The band intensity shows the nature of antigen release from the microparticles and found that there were no damage occurs during microencapsulation (Fig.3). The percentage of antigenically active typhoid antigens was found to be $91.5 \%$ by ELISA after entrapment with $8 \%$ of starch and $0.5 \%$ of stabilizing agent (Glutaraldehyde).

Compatibility studies using IR spectrum

The IR spectrum of Typhoid antigen encapsulated starch microparticles, indicates that the antigen loaded microparticles and antigen unloaded with the characteristics peaks observed in $3415 \mathrm{~cm}-1,1650 \mathrm{~cm}-1,1159 \mathrm{~cm}-1$ (Fig.4 a \& b).

In vitro release studies

It shows the gradual release of entrapped antigen and peak release was observed on (2 to 20 hrs). The release was pulsated for $6 \mathrm{hrs}$ and this was confirmed by the Bronsted Lowry's methods. Based on the percentage of total protein and antigenic active protein, the release from microparticles was ustained antigenic release for a prolonged period (Fig. 5). Large amount of typhoid antigen was incorporated during the microencapsulation process, which increase the loading capacity. Some of earlier researcher reported that the molecular weight of the polymer had a great impact on the formulation of microencapsulation. However, further studies with some modification are needed to get better formulation to release active typhoid antigen.

\section{Immunogenicity studies}

The principle has been extended for the detection of antigens. The antigen may be attached to red blood cell surface or antibodies can be presented to these cells. Agglutination tests are useful for assaying the amount of antibody present in a sample. For
Research article

CIndian Society for Education and Environment (iSee)
"Improved typhoid vaccine" http://www.indjst.org
Nirmala et al. Indian J.Sci.Technol. 
Table 2. The effect of cross linking (stabling agent) concentration

\begin{tabular}{|c|c|c|c|c|}
\hline Polymer & $\begin{array}{c}\text { Polymer } \\
\text { concentration }\end{array}$ & $\begin{array}{l}\text { Stabilizing } \\
\text { agent }\end{array}$ & $\begin{array}{l}\text { Concentration of } \\
\text { stabilizing agent }\end{array}$ & Size and shape \\
\hline \multirow{5}{*}{ Starch } & \multirow{5}{*}{$8 \%$} & \multirow{5}{*}{$\begin{array}{l}\frac{0}{0} \\
\frac{1}{0} \\
\frac{0}{0} \\
\frac{0}{0} \\
\frac{0}{J} \\
\frac{3}{0}\end{array}$} & $0.1 \%$ & Micro particles are not formed \\
\hline & & & $0.2 \%$ & Micro particles are not formed \\
\hline & & & $0.3 \%$ & $\begin{array}{l}\text { Micro particles formed but } \\
\text { unstable }\end{array}$ \\
\hline & & & $0.4 \%$ & $\begin{array}{l}\text { Micro particles are formed but } \\
\text { not homogeneous }\end{array}$ \\
\hline & & & $0.5 \%$ & Smooth particles are formed \\
\hline
\end{tabular}

this, agglutination test was carried out with blood sample by precipitating the RBC. The dilution ratio of 1: 50 (Table 5) showed agglutination factor and the titer value was 50. The amount of antigen assessed by immunoprecipitation assay was found to be $5 \mathrm{l} \mu \mathrm{g}$.

Table 3. Effect of loading on microparticle formulation

\begin{tabular}{|c|c|c|c|}
\hline $\begin{array}{c}\text { Characteristic antigen } \\
\text { encapsulated starch micro } \\
\text { particles }\end{array}$ & \multicolumn{2}{|c|}{ Size } & \multirow{2}{*}{ Comments } \\
\cline { 2 - 3 } & $\begin{array}{c}\text { Before } \\
\text { loading }\end{array}$ & $\begin{array}{c}\text { After } \\
\text { loading }\end{array}$ & \\
\hline $\begin{array}{c}\text { Typhoid antigen encapsulated } \\
\text { starch micro particles }\end{array}$ & $76 \mu \mathrm{m}$ & $10-50 \mu \mathrm{m}$ & $\begin{array}{c}\text { Size reduced, smooth micro } \\
\text { particles are formed }\end{array}$ \\
\hline Dummy batch & $80 \mu \mathrm{m}$ & $20-45 \mu \mathrm{m}$ & $\begin{array}{c}\text { Size reduced, smooth micro } \\
\text { particles are formed }\end{array}$ \\
\hline
\end{tabular}

In vivo immune response

Based on the release of antigen from starch microparticles in vitro, further release of antigen was confirmed in vivo in the Wister rat, where it was capable of forming antigen depot and the antigen was released slowly from the site of injection. Generally, in animal system, small microparticles can be directly taken up into

Table 4. Physical characteristic of prepared micro particles

\begin{tabular}{|l|c|c|c|c|}
\hline \multicolumn{1}{|c|}{ Batch } & $\begin{array}{c}\text { Particle size } \\
(\mu \mathrm{m})\end{array}$ & $\begin{array}{c}\text { Loading } \\
\text { capacity }(\%)\end{array}$ & $\begin{array}{c}\text { Loading } \\
\text { efficiency }(\%)\end{array}$ & $\begin{array}{c}\text { Swelling } \\
\text { ratio }\end{array}$ \\
\hline $\begin{array}{l}\text { Dummy } \\
\text { microparticles }\end{array}$ & $45.21 \pm 0.088$ & - & - & $3.61 \pm 0.14$ \\
\hline $\begin{array}{l}\text { Antigen loaded } \\
\text { Micro particles }\end{array}$ & $43.34 \pm 0.094$ & $44.76 \pm 041 \%$ & $75.17 \pm 1.56 \%$ & $3.27 \pm 1.24$ \\
\hline
\end{tabular}

Values are expressed as mean $\pm S D(n=5)$

macrophages by phagocytes. However, larger microparticles need to undergo biodegradation before phagocytosis that can occur; at this stage, microparticles can be covered with one or several layers of macrophages as a consequence of the wound healing response to injected particles. The immunoglobulin (Fig. $6,7,8$ ) shows the increased level of $\lg A$, $\lg M, \lg G$ on $15^{\text {th }}$ and $35^{\text {th }}$ days.

In immunoglobulin titer values, the $\lg A$ shows the moderate responses (Fig. $7 \& 8$ ) where as IgG shows the moderate effect till $15^{\text {th }}$ and $35^{\text {th }}$ day (Fig. 7), IgM was increased in conventional typhoid antigen (Fig. 8). IgE was increased in $35^{\text {th }}$ day. Anti-typhoid antigen shows the decreased effect in the antigen loaded potato starch microparticles (Fig. 7).

Conclusion

This research work mainly focused on the enhanced immune response using Research article CIndian Society for Education and Environment (iSee)
Table 5. Hemagglutination test

\begin{tabular}{|c|c|}
\hline Master dilution & $1: 12.5$ \\
\hline $2^{\text {nd }}$ dilution & $1: 25$ \\
\hline $3^{\text {rd }}$ dilution & $1: 50$ \\
\hline $4^{\text {th }}$ dilution & $1: 100$ \\
\hline $5^{\text {th }}$ dilution & $1: 200$ \\
\hline $6^{\text {th }}$ dilution & $1: 400$ \\
\hline $7^{\text {th }}$ dilution & $1: 800$ \\
\hline \multicolumn{2}{|c|}{ "Improved typhoid vaccine" } \\
http://www.indjst.org
\end{tabular}
The immunogenicity studies $n$ hemagglutination test and immunoprecipitation test for the antigen and antibody. The enhance immunogenicity of Typhoid vaccine loaded potato starch microparticles was determined by antibody induction method. This shows the good immune response till 35th day. However, it is clear that more detailed investigations are necessary to clarify the effect of matrix polymer on antigen stability and enhanced immunogenicity during microspheres preparation and antigen releasing procedures and the effect of immunization of animals with microspheres formulation.

\section{Acknowledgements}

We would like to thanks the Serum Institute of India for providing free gift sample of vaccine and IIT Madras for SEM analysis. Authors are grateful to Dr. K. S. Lakshmi and Department of 
Fig.3. SDS-PAGE analysis of antigen

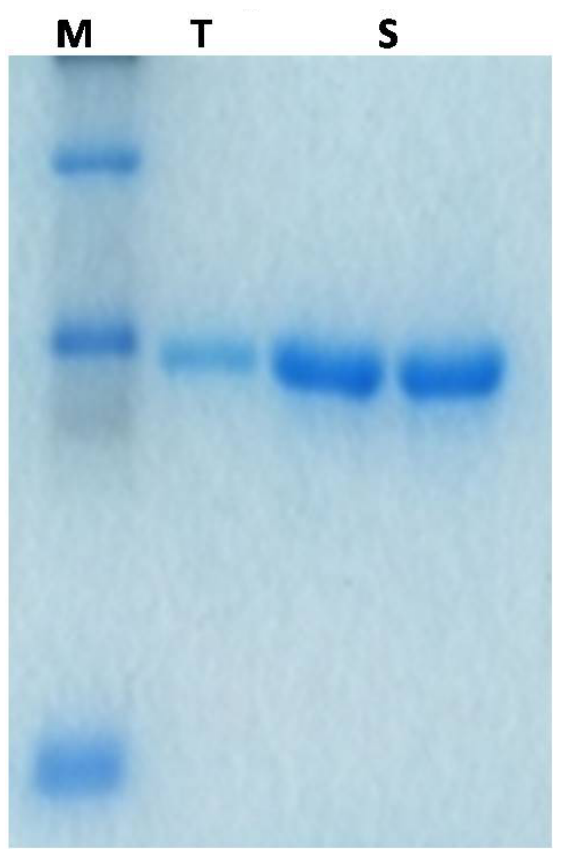

M: Marker protein; T: Anigen extracted from microparticles S:Conventional antigen
Fig.4. IR spectrum of antigens

\section{a. Antigen unloaded microparticles b. Antigen loaded microparticles}
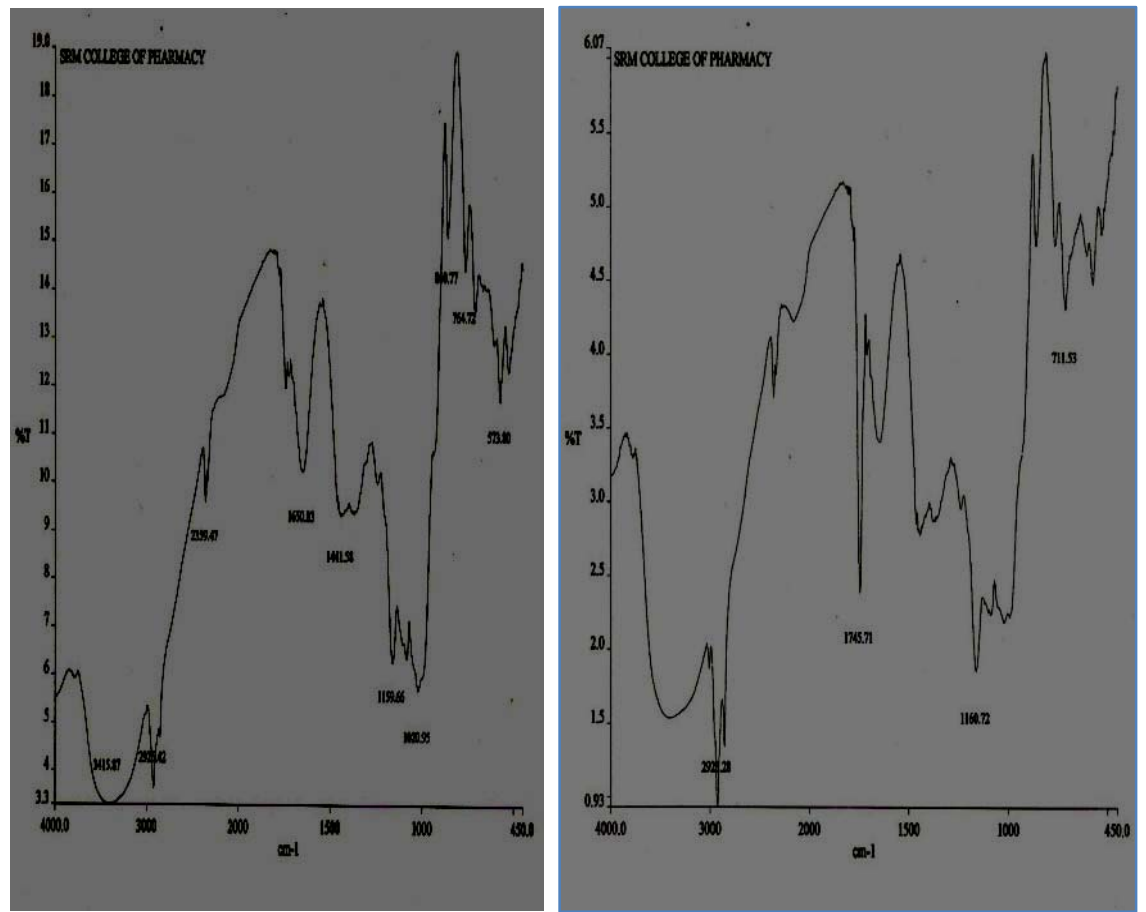

Fig. 5. Time period (hrs) Vs Percentage release of Antigen (O. D). Each point indicates that the antigen encapsulated microparticles releases the antigen for prolong period)

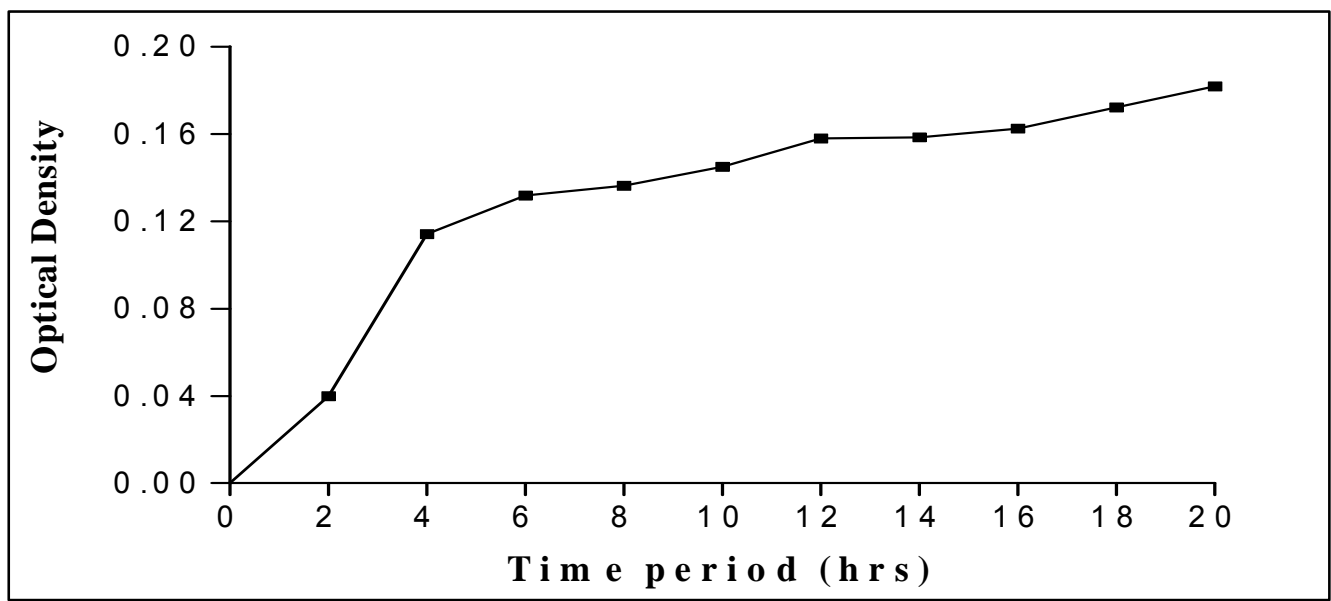


Indian Journal of Science and Technology

Fig. 6. immunoglobulin Titre( IgG, IgA, IgM, IgE)

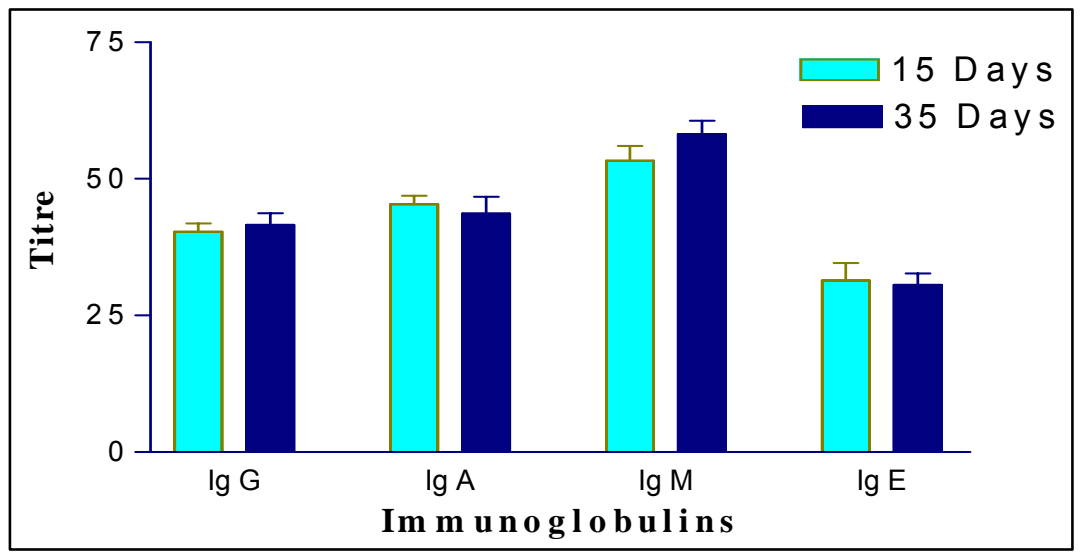

Fig. 7. Immunoglobulin titer Typhoid encapsulated Potato Starch (IgG, IgA, IgM, IgE, AntiTy-Ag) It indicates that increase antigenic responses of IgG, IgA, IgM, Ig E, Antityphoid antigen till $35^{\text {th }}$ day

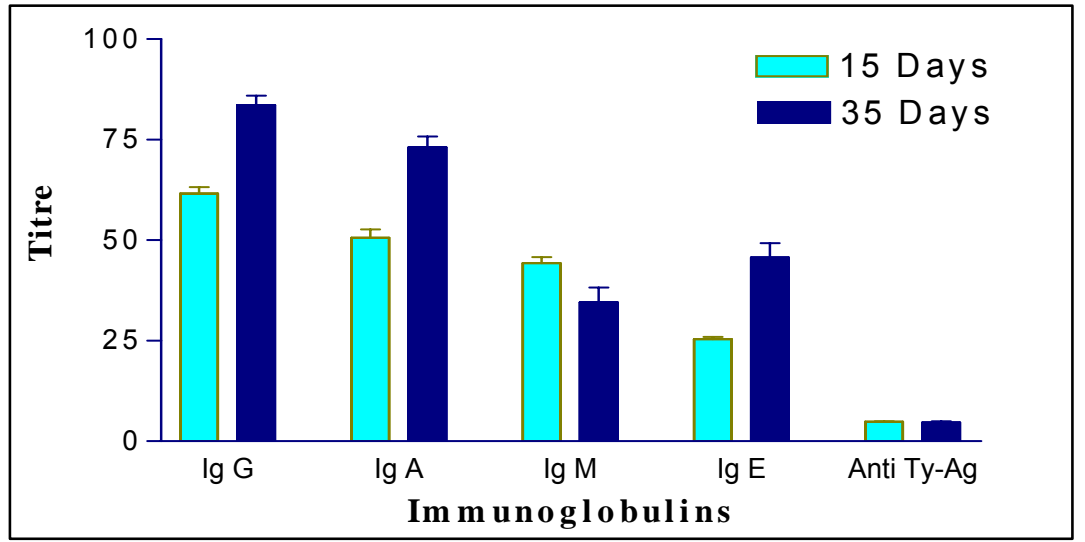

Fig.8. Immunoglobulin titer (Conventional Typhoid Vaccine). It indicates that the optimum release of an antigen with anti typhoid antigen

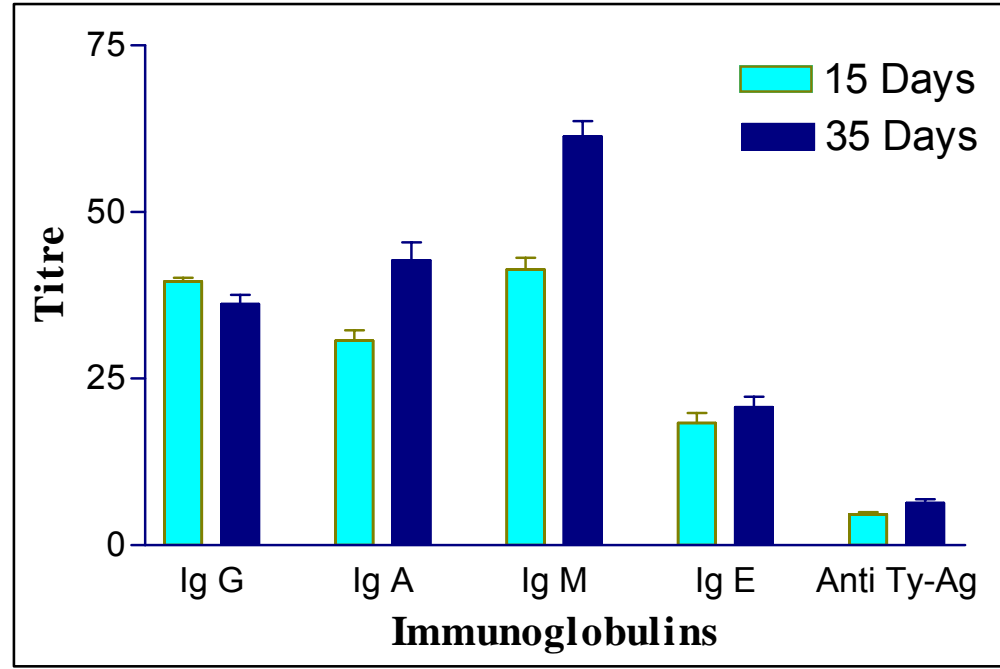

Vol. 4 No. 4 (April 2011)

ISSN: 0974- 6846

\section{References}

1. Davis SS (1998) Polymeric system for vaccine delivery. Res. Immunol. 149, 49-52.

2. Dubey RC (2006) Quantitative protein estimation. In: Textbook of Biotechnology. S.Chand \& Company LTD, RamNagar, New Delhi.pp: 634-635.

3. Fiegel J, Fu J and Hanes J (2004) Controlled delivery of drug by using biodegradable polymer.J. Control. Release. 96, 411-423.

4. Hans J and Hagan D (1998) Preparation and Characterization of polymeric antigen delivery system for parenteral administration. Adv. Drug Del. Rev. 28, 97-119.

5. Kalara SP, Naithani N, Mehta SR and Swamy AJ (2003) Current trends in management of typhoid fever. 59, 130-135.

6. Lewis DH, Chasin M and Langer R (1998) Biodegradable polymers as antigen delivery systems. Adv. Drug Del. Rev. 27, 91116,Microparticulate delivery system potential drug/ Vaccine carries J Controlled Delivery Sytem 1(2) 69-75

7. Morein B, Villacrks EM and Sjblander A (1996) Novel adjuvants and vaccine delivery systems. Vet. Immunol. Immunopathol. 54, 373-384.

8. Sacchez A, Villamayor B, Guo Y, Mclver J and Alonso MJ (1999) Formulation strategies for the stabilization of tetanus toxoid in. Poly (D, L-lactatide-co-glycolide) microspheres. Intl.J. Pharmaceutics. 185, 255-266.

9. Seong SY, Cho NH, Chun $\mathrm{KH}$ and $\mathrm{Kim} \mathrm{YH}$ (1998) Novel mucosal immunization with polysaccharide protein conjugates entrapped in alginate microspheres. J. Controlled Release. 53, 215-224.

10. Singh M and O' Hagan D (1998) The preparation and characterization of polymeric antigen delivery systems for oral administration. Adv. Drug Delivery Rev. 34, 285-304.

11. Singh $M$, O'Hagan $D$, Julia $R$, Briones $M$, Ugozzoli M, Kazzaz J and Barackman (1998) A combination of biodegradable micro particles and MF59 as systemic adjuvant for recombinant IgD from HSV-2. Vaccine. 19, 16. 12. Yadav AV and Montae HH (2008) Development of biodegradable starch microsphere for intranasal delivery. Indian J Pharm Sci. 70(2), 170-174

Pharmaceutical Biotechnology SRM College of Pharmacy for the needful support. 